\title{
DOI 10.17150/2308-6203.2021.10(4).597-613
}

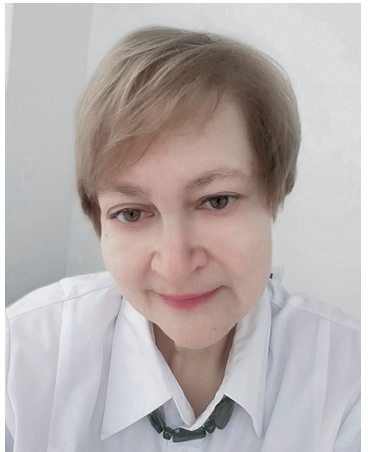

\section{Демина Ирина Николаевна}

Доктор экономических наук, профрессор, заведующий кафедрой

Кафедра журналистики и маркетинговых технологий, Байкальский государственный университет, г. Иркутск, Российская Федерация, e-mail: idemima.irk@mail.com

Irina N. Demina

D.Sc. in Economics, Professor, Head of Department

Department of Journalism and Marketing Technologies, Baikal State University, Irkutsk, Russian Federation, e-mail: idemima.irk@mail.com

\section{Наукометрические показатели медиаисследователей в электронной библиотеке e-Iibrary}

\footnotetext{
Аннотация. Статья является продолжением предыдущих исследований автора в области наукометрии медиаисследователей по тематике «Массовая информация. Журналистика. СМИ» по версии российской научной электронной библиотеки e-library и российского индекса научного цитирования. Методологией явился сплошной анализ персоналий первой сотни авторов, ранжированной по уроню һ-индекса в 2020 г. по сравнению с 2017 г., а по некоторым аспектам - и с 2016 г. В статье проанализированы изменения h-индекса за исследуемые годы, изменение географии авторов по федеральным округам и городам РФ, их научный статус, распределение докторов и кандидатов наук по научным специальностям в соответствии с присужденной степенью, а также распределение персоналий рейтинга по фактическим научным интересам и читаемым им дисциплинам в аффрилированных с ними научно-образовательных организациях. Сделаны выводы о важности наукометрических показателей для авторов и научно-образовательных организаций для определения их места в научном сообществе, востребованности тематики и конкретных работ авторов в общем научном ландшафрте, материальном стимулировании. В то же время отмечено, что система наукометрических показателей изменяется: возможно, h-индекс, число опубликованных работ и количество цитирований в РИНЦ останутся в качестве объекта исследований историками науки для определения общего места российских (и советских) ученых в тренде развития науки, а в дополнение или на смену им придут другие показатели. Одним из них выступает недавно введенный в перечень наукометрических показателей «процентиль». Исследования значений наукометрических показателей останутся актуальными и в дальнейшем.

Ключевые слова. Массовая коммуникация, журналистика, СМИ, медиаисследования, наукометрические показатели, научно-образовательные школы.

Информация о статье. Дата поступления 12 сентября 2021 г.; дата принятия к печати 8 ноября 2021 г.; дата онлайн-размещения 15 декабря 2021 г.
} 


\title{
Scientometric Indicators of Media Researchers in the e-library
}

\begin{abstract}
This study extended the author's previous research in the field of scientometrics of media researchers on the topic "Mass information. Journalism. Mass media" in Russian electronic library and Russian Science Citation Index. The methodology was a census of the personalities of the first hundred authors ranked by the level of the h-index in 2020 compared to 2017, and in some aspects - from 2016. The study analyzed the changes in the h-index over the years under study, changes in the authors' geography by federal districts and cities of the Russian Federation, their academic position, the distribution of doctors and candidates of sciences in scientific majors in accordance with the awarded degree, as well as the distribution of rating personalities by actual scientific interests and taught courses in their affiliated scientific and educational organizations. The study revealed the importance of scientometric indicators for authors and scientific and educational organizations to determine their place in the academic community, the relevance of topics and authors' research in the general academic landscape, and material incentives.

At the same time, it was noted that the system of scientometric indicators is changing: perhaps the h-index the number of published works and the number of citations in the RSCl will remain as an object of research by historians of science to determine the common place of Russian (and Soviet) scientists in the science development, and in addition or to replace them there will be new indicators. One of them is the "percentile" recently introduced into the list of scientometric indicators. Studies of the values of scientometric indicators will remain relevant in the future.

Keywords. Mass communication, journalism, media, media research, scientometric indicators, scientific and educational schools.

Article info. Received September 12, 2021; accepted November 8, 2021; available online December 15, 2021.
\end{abstract}

\section{Введение}

С начала 2000-х гг. в практику оценки эффективности работы научно-образовательных учреждений, коллективов кафедр, научно-исследовательских лабораторий, каждого конкретного исследователя активно внедрялись наукометрические показатели, в том числе h-индекс (индекс Хирша). С 2010-х гг. основной наукометрической базой в России является научная электронная библиотека (НЭБ) e-library. Библиотека активно развивается и в настоящее время, вводятся новые показатели, налажено сотрудничество с международными наукометрическими базами данных. В российской базе зарегистрированы практически все отечественные (и некоторые зарубежные) авторы научных работ по 69 научным отраслям. Одним из основных научно-метрических показателей и стал h-индекс. Тогда же сама база стала интересным объектом исследования для анализа деятельности научно-образовательных организаций и самих авторов.

В результате анализа данных e-library можно делать выводы об активности авторов, организаций в динамике, данные базы становятся инструментом рефлексии авторов, определении места, занимаемого 
ученым в своеобразной иерархии в разных аспектах (по h-индексу, числу цитирований и т.д.). Результаты анализа некоторых показателей публикационной активности были опубликованы автором в нескольких статьях с 2014 г. по 2018 г. [1; 2].

Исследования оказались полезны для описания научно-образовательных школ в России [3; 4], статистического анализа диффреренциации российских регионов по уровню публикационной активности [5], сравнения публикационной активности вузов в отдельных регионах России [6]. Дальнейший анализ будет также актуален как для подобных научных целей, так и для определения места каждого автора в иерархии самых цитируемых ученых России, своеобразной саморефлексии авторов, реализации PR-мероприятий ученых и представляемых авторами научно-образовательных организаций. Исследование полезно также для выстраивания приоритетов в управлении учеными показателями собственной публикационной активности, видении возможностей роста h-индекса, выстраивания стратегий как персонально авторов, так и научных подразделений образовательных и научных организаций.

\section{Методика исследования}

В научной электронной библиотеке e-library зарегистрированы авторы по 70 отраслям науки. По направлению «Массовая коммуникация. Журналистика. Средства массовой информации» в библиотеке присутствуют 1676 ученых ${ }^{1}$. Каждый автор имеет право указать при регистрации 3 научных направ-

\footnotetext{
${ }^{1}$ Научная электронная бибилиотека eLibrary. 2021. URL:https://www.elibrary.ru.
}

ления, но в список включаются ученые, приоритетным направлением которых является указанное. Заинтересованные авторы и научно-образовательные организации имеют возможность по итогам прошедшего года отследить результаты каждого ученого по нескольким показателям. В библиотеке выстраивается иерархия авторов по следующим показателям:

1. Н-индекс:

- по публикациям в РИНЦ (публикации, включенные в российский индекс научного цитирования);

- по всем публикациям в e-library;

- по публикациям в ядре РИНЦ (суммарно в Skopus, WoS, RSCI Russian Science Citation Index);

2. Число цитирований также по всем базам.

3. Число публикаций по всем перечисленным базам.

Такой материал позволяет провести исследования по разным показателям. Данное исследование основано на анализе авторов по показателю h-индекса, рассчитанному по публикациям в РИНЦ. Объектом исследования являются характеристики авторов, попавших в первую сотню (назовем ее Топ-100) по этому показателю. Это позволяет сохранить преемственность с предыдущими исследованиями. Методами исследования являются сравнительный анализ показателей в динамике (2016, 2017, 2020 гг.). В данной статье исследуется географическая локация авторов, их преимущественные научные интересы в рамках направления «Массовая коммуникация. Журналистика. Средства массовой информации», обновление Топ-100 по сравнению с предыдущими периодами. 


\section{Результаты исследования}

В настоящее время наукометрический показатель h-индекс остается важнейшим для оценки и анализа научной деятельности ученого как для самого автора, так и для аффилированной с ним научно-образовательной организации. Кривые h-индекса, построенные по результатам прошлых исследований и данного исследования Топ-100 авторов за 2016, 2017 [2] и 2020 гг., показаны на рис. 1.

Для того, чтобы попасть в Топ100, минимальный h-индекс в 2016 г. равнялся 6 , в 2017 г. - 8, в 2020 г. вырос до 10. В 2016 г. на первом месте оказался автор с h-индексом 26, в 2017 г. - 34, в 2020 г. - 32.

Средневзвешенный по числу авторов с одинаковым показателем h-индекс в 2016 г. составлял 9,3, в 2017 г. - 12,6, по итогам 2020 г. достиг 12,92. Наблюдается рост h-индекса, однако за три года его средневзвешенное значение выросло незначительно: всего за год с 2016 по 2017 г. он вырос более чем на треть (точнее на 35 \% - 9,3 до 12,6), тогда как за три года увеличился всего на 2,5 \% (с 12,6 до 12,92). Причины этого обстоятельства лежат в двух областях. Во-первых, инструментальные: в начале периода еще не накопилась достаточная база для представления всех авторов в базе, и сама база РИНЦ e-library тогда не имела накопленного опыта в верификации показателей и четкого их определения. К настоящему периоду эти недостатки нивелированы.

Второй комплекс причин связан с самими авторами, которые были гораздо более мотивированы в на-

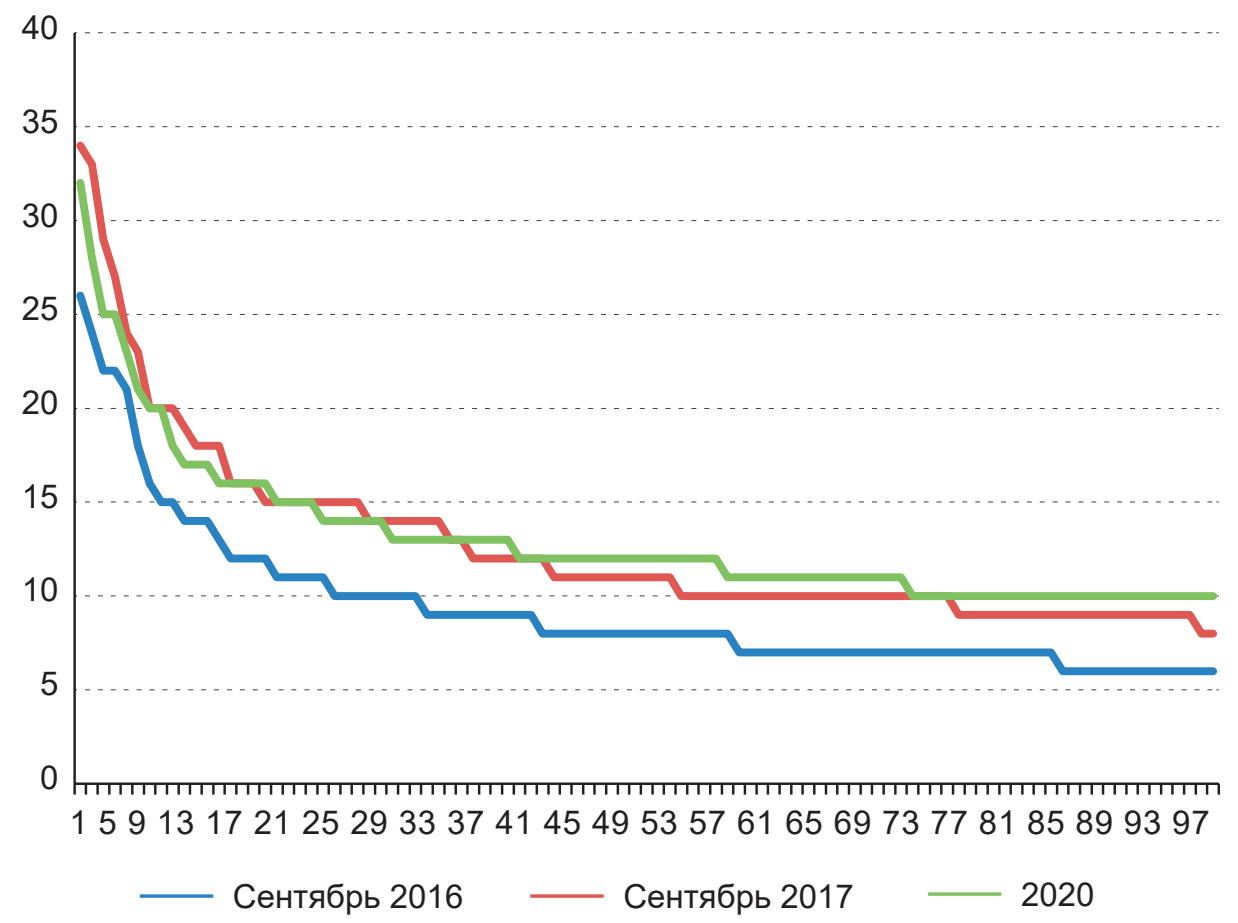

Рис. 1. Н-индекс персоналий Топ-100 в 2016, 2017 и 2020 гг. 
чале 2010-х гг., нежели в настоящее время. Для материального стимулирования научно-педагогических работников наукометрические показатели имеют большое значение. От них зависит премирование, возможность включения в Диссертационные советы, участие в конкурсах на замещение вакантных должностей и т.д. Для этого можно воспользоваться любыми из существующих показателей, h-индекс - лишь один из них, весьма спорный [7; 8]. Кроме того, даже если он принимается во внимание, то непонятно, какой именно: только в НЭБ һ-индекс рассчитывается тремя способами (по публикациям в РИНЦ, по всем публикациям в e-library, по публикациям в ядре РИНЦ), кроме того, этот показатель рассчитывается в Scholar.google.ru, в МНБД Scopus и WoS и т.д. Именно поэтому в настоящее время h-индекс стал лишь вспомогательным инструментом. В то же время рейтинг ученых даже по одному из показателей h-индекс (в любой базе или по одному из способов его определения) остается индикатором научных достижений исследователей и помогает определить траекторию дальнейшей стратегии как автора, так и представляемой им организации.

В исследовании был проведен анализ структуры авторов, составляющих Топ-100, включая их научный статус, географическое положение афффилированных с авторами научно-образовательных организаций и научные интересы.

В 2020 г. по сравнению с 2017 г. список авторов, попавших в первую сотню, обновился на $63 \%$, т.е. в него оказались включены 63 (из 100) новых фигуурантов. Любопытно, что из 63 новых фригурантов 14 (22 \%) ушли из жизни до включения их в базу НЭБ (с 1978 г.). Вопрос о возможности и «легитимности» включения в базу ушедших из жизни ученых остается весьма деликатным. Такое положение дел, возможно, приведет к тому, что в дальнейшем построение рейтингов и их анализ станет, скорее, объектом исследований истории науки, нежели показателем современного положения дел в той или иной научной отрасли и тематики, по которой выделяются группы авторов (в нашем случае это «Массовая коммуникация. Журналистика. СМИ»). В целом же такой рейтинг (с возможностью включения в него ушедших авторов) подчеркивает научные достижения российских (и советских) ученых, уходя вглубь времени и подчеркивает научную значимость афффилированных с этими авторами организаций.

Продолжая преемственность с предыдущими исследованиями, в настоящем анализе был произведен анализ географической структуры авторов Топ-100 в 2020 г. в сравнении с данными предыдущих исследований [2] (рис. 2). На этом рисунке авторы структурированы по федеральным округам РФ.

Диаграмма на рисунке наглядно представляет изменения в географической структуре: если до 2017 г. наблюдалось последовательное снижение доли авторов первой сотни, представляющих Центральный федеральный округ, то в 2020 г. доля таких авторов превысила половину (55 \%. Данные в процентах полностью совпадают с абсолютными данными, так как анализируются 100 авторов) всех фригурантов. Немного, но постоянно увеличивается (хоть и остается примерно на одном уровне) 


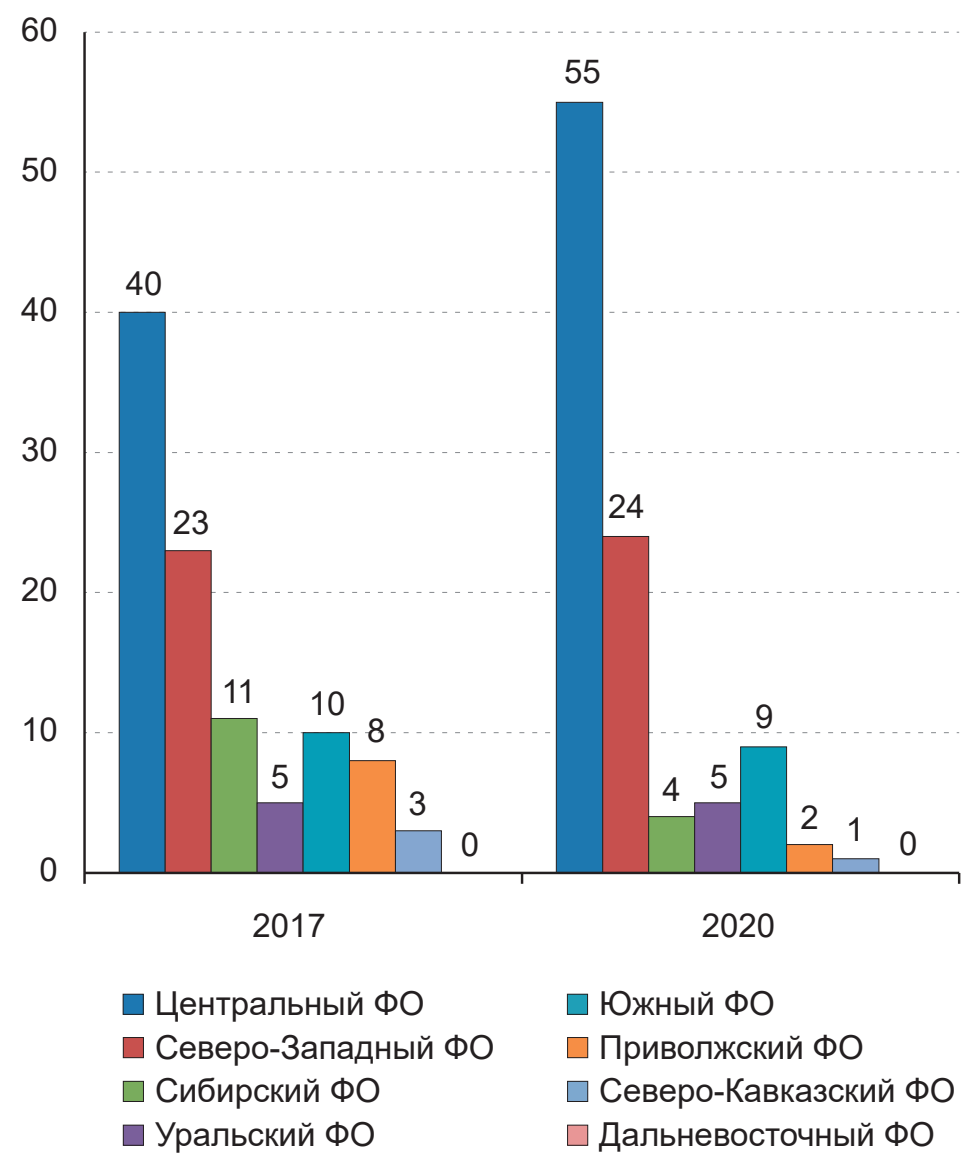

Рис. 2. Географическая структура авторов Топ-100 по федеральным округам РФ

удельный вес в структуре представителей Северо-Западного федерального округа (23 фигурантов в 2017 и 24 - в 2020 г.). Так же постоянным остается представительство Южного (10 и 9 соответственно) и Уральского (5 авторов и в 2017, и в 2020 г.) федеральных округов. Основным трендом является постоянное уменьшение долей авторов из Сибирского (с 11 до 4), Приволжского (с 8 до 2), Северо-Кавказского (с 3 до 1) и Дальневосточного (с 3 до 1) фредеральных округов.

Более детально (по городам России) географическая структура показана на рис. 3.
Рисунок показывает более детальное географическое структурирование персоналий Топ-100. За три года значительно сократилось число городов, представленных авторами первой сотни: в 2017 г. в рейтинге присутствовали представители 24 городов, в 2020 г. - 15. Абсолютное доминирование показывают авторы из столицы - их число выросло с 34 до 45 чел. Стабильным остается количество авторов из Санкт-Петербурга (23 и 24 чел. соответственно). Третье место по числу представителей Топ-100 (5 ученых) в 2020 г. делят Воронеж и Ростов- 
Вопросы теории и практики журналистики. 2021. Т. 10, № 4. С. 597-613

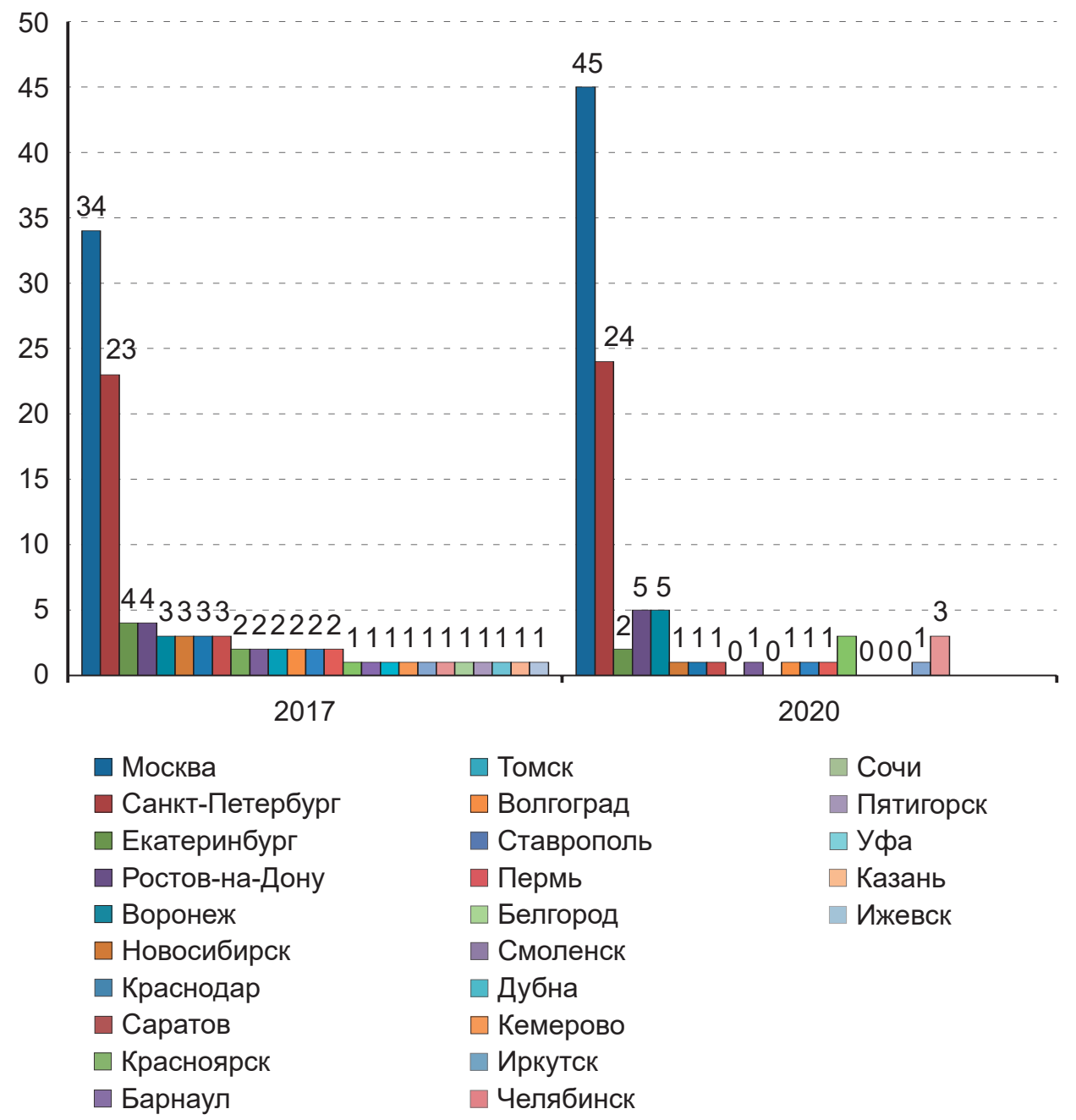

Рис. 3. Географическое распределение авторов Топ-100 по городам России

на-Дону. По 3 автора в 2020 г. - из Челябинска и Белгорода, 2 - из Таганрога и Екатеринбурга. Остальные города (Тамбов, Краснодар, Волгоград, Барнаул, Иркутск, Новосибирск, Саратов, и Пермь) представлены каждый одним автором. Такой растущий монополизм Центрального и Северо-Западного федеральных округов, а именно, Москвы и СанктПетербурга объясняется рядом причин, которые будут раскрыты ниже.
О динамике изменения научного статуса (присужденной им научной степени) авторов Топ-100 можно судить по рис. 4.

Если о качество работ авторов судить по присужденным им научным степеням, то за три года структурный статус Топ-100 изменился весьма заметно: за три года в составе Топ-100 количество докторов наук выросло с 62 до 76, соответственно кандидатов - сократилось не слиш- 


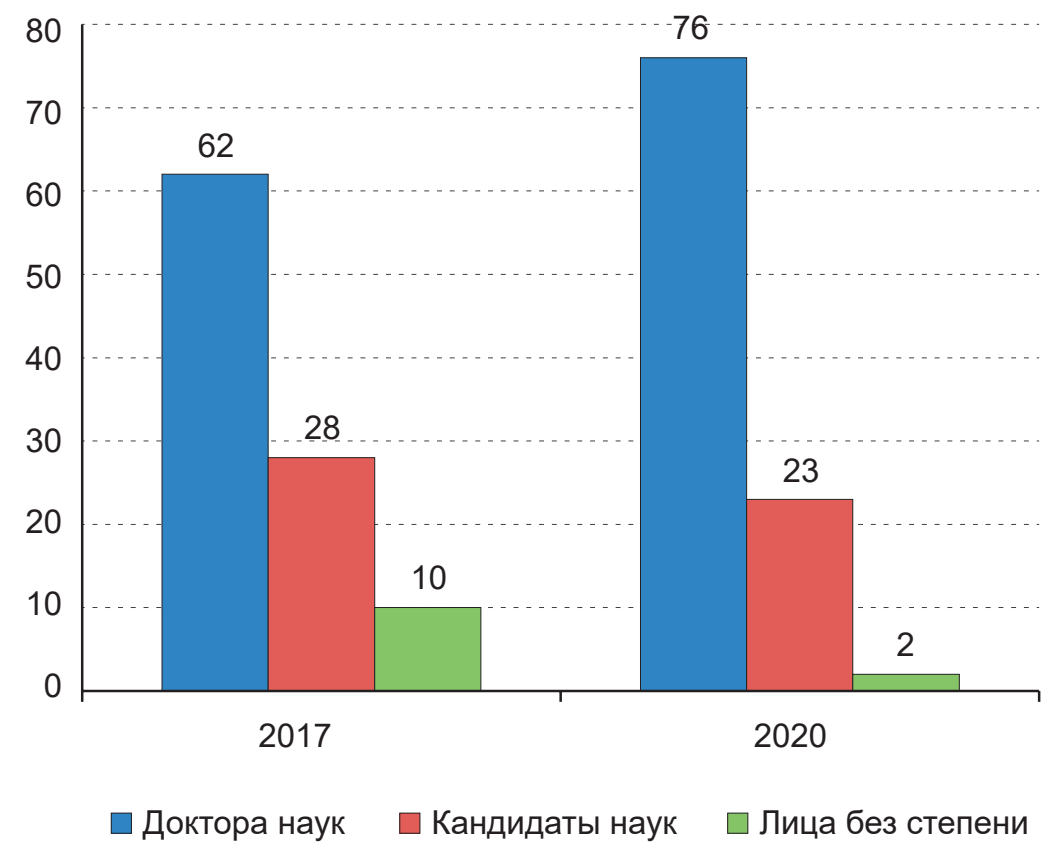

Рис. 4. Научный статус авторов Топ-100 в 2017 и в 2020 гг.

ком значительно - с 28 до 23, а лиц без научной степени - уменьшилось с 10 до 2. В целом это показывает рост качества научных работ в НЭБ. За исследуемое время возросло количество авторов, зарегистрированных в e-library. Кроме того, доктора наук, возможно, признали ценность собственных наукометрических показателей для собственного продвижения, и мотивация роста этих показателей возросла с внедрением в вузах эффрективных контрактов, системы формирования зарплаты и премирования в зависимости от публикационной активности.

Еще одной причиной является переход отечественных научных журналов (вслед за журналами, включенными в международные наукометрические базы данных Skopus и Web of Science) на бизнес-модель, предусматривающую оплату публикаций авторами. Это привело к увеличению числа соавторов одной статьи, иногда из разных географических локаций и научно-образовательных организаций (так называемые коллаборации). Руководителем таких научных коллективов, как правило, становятся именно доктора наук. Грантовое фринансирование науки приводит к возникновению таких научных коллективов, и одной из статей расходов таких грантов является фринансирование публикаций статей. Вероятность получения грантов повышается многократно, если коллектив опирается на организации с многолетним научным опытом, ученых, имеющих многолетнюю научную репутацию, способных организовать научную работу и определить методологическую базу таких исследований. Этим же объясняется тренд монополизации науки (в данном случае мы имеем в виду наше направление «Массовые коммуникации. Журналистика. СМИ»). 
В исследовании авторы были проанализированы в соответствии с научными направлениями, по которым им были присвоены научные степени. Структура персоналийдокторов наук Топ-100 в 2017 и в 2020 гг. показана на рис. 5, кандидатов наук - на рис. 6.

В предыдущих исследованиях было констатировано, что в структуре научных специальностей лиц со степенями наблюдался их чрезвычайно широкий спектр. Авторы регистрировались в НЭБ по трем научным направлениям, и в рейтинг попадали ученые, для которых массовые коммуникации, журналистика, СМИ являлись не всегда основным направлением. В настоящее время процедура включения ученых в НЭБ и подведения ежегодных результатов наукометрических показателей стала более упорядоченной и верифицированной.

Лицам, защищающим диссертации (и докторские, и кандидатские) по специальности 10.01.10 Журналистика присуждаются степени либо филологических, либо политических наук. В рейтинге за 2017 г. среди

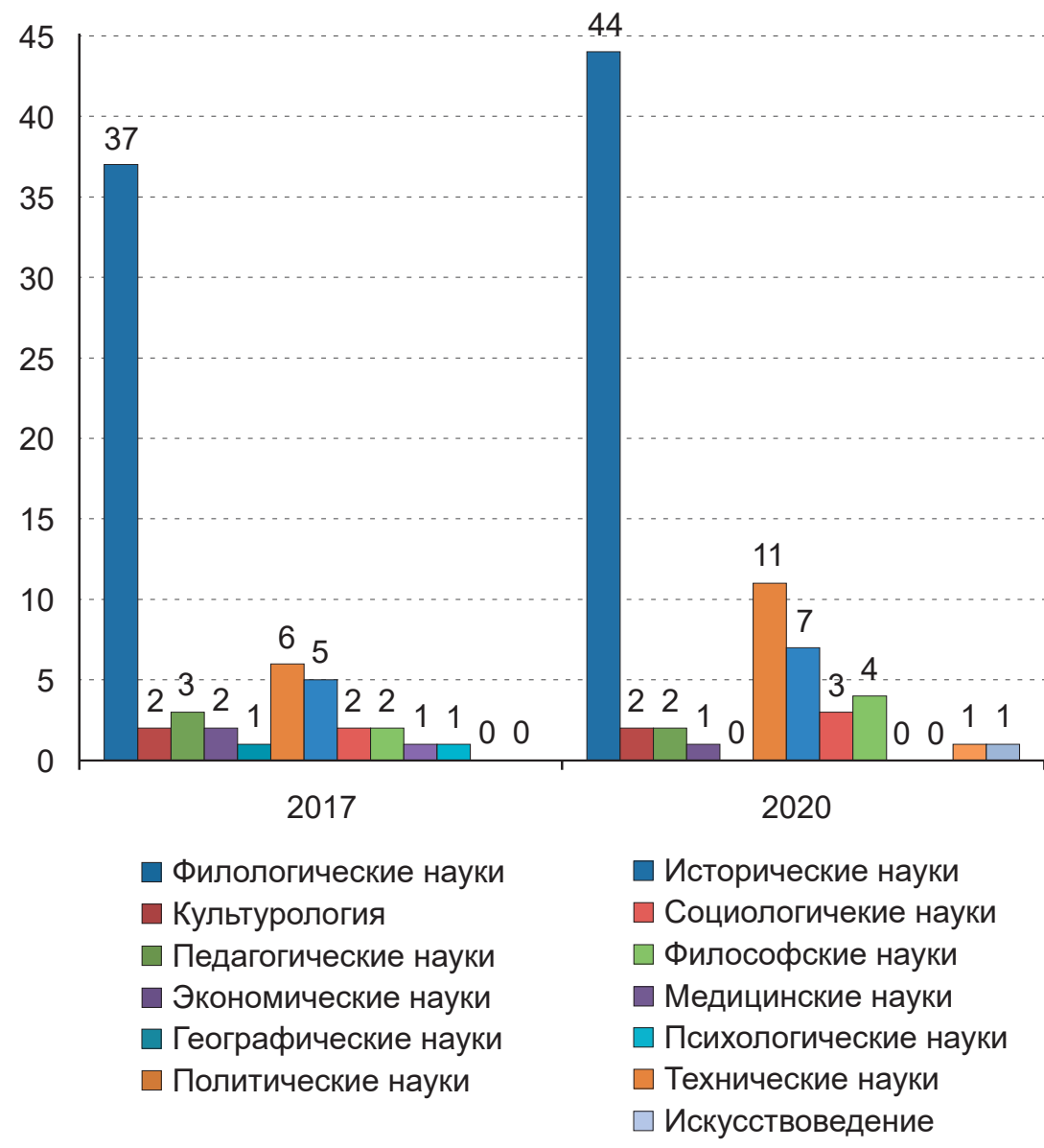

Рис. 5. Структура персоналий Топ-100 докторов наук по научным направлениям в 2017 и 2020 гг. 


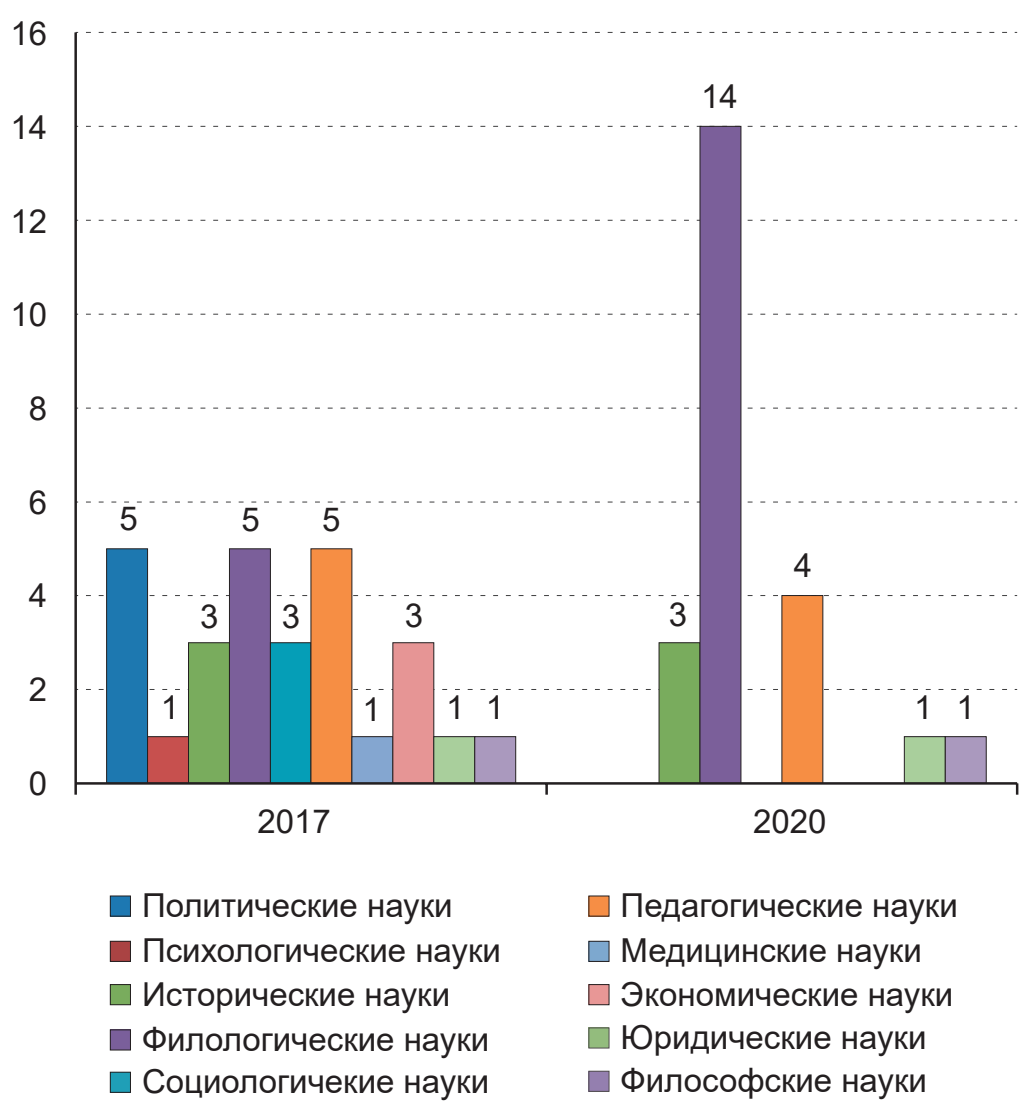

\section{Рис. 6. Структура персоналий Топ-100 кандидатов наук по научным направлениям в 2017 и 2020 гг.}

докторов наук присутствовали представители 11 научных специальностей, за 2020 г. - 10. Из рейтинга исчезли доктора географических, медицинских и психологических наук, появились, в свою очередь, доктора технических наук и искусствоведения. За три года в первой сотне число докторов филологических наук возросло с 37 до 44 чел., политических - с 6 до 11. На третьем месте - доктора исторических наук (их число выросло за три года с 5 до7 чел.), затем -философских (число выросло с 2 до 4 чел.). Докторов социологических наук - 3 чел. Остальные (по 1-2 чел.) - доктора культурологи, педагогических и экономических наук.

Среди кандидатов изменение рейтинга более показательно - в 2017 г. в первой сотне фригурировали представители 10 научных специальностей, в 2020 г. - 5. В рейтинге остались кандидаты фрилологических наук (их число выросло с 5 до 14 чел.), педагогических (число упало с 5 до 4 чел.), исторических (не изменилось - 3 чел.), юридических и философских (было и осталось по 1 чел.). В рейтинге 2020 г. по сравнению с 2017 г. нет кандидатов политических, психологических, социологических, ме- 
Вопросы теории и практики журналистики. 2021. Т. 10, № 4. С. 597-613

дицинских и экономических наук. С одной стороны, это говорит о более точной верификации данных НЭБ, с другой - возможном «обеднении» направлении исследований в нашей научной отрасли, которая по природе своей является междисциплинарной.

Для более подробного анализа были проанализированы фрактические области научных интересов фигурантов первой сотни авторов в научной отрасли «Массовые коммуникации. Журналистика. СМИ». В предыдущем анализе [2] в результате сплошного исследования фигурантов Топ-100 2017 г. все они были разделены на несколько направлений. Данные были взяты из открытых источников путем поиска в Сети каждого фригуранта по аффилированным с ним научно-образовательным организациям. Для преемственности в данном исследовании персоналии из рейтинга 2020 г. отнесены к тем же научным областям и преподаваемым дисциплинам (если персоналии - представители образовательных организаций). Полученные данные представлены в таблице и, для большей наглядности - на рис. 7.

Данные таблицы и диаграмма показывают, что фактические научные интересы первой сотни рейтинга авторов «Массовые коммуникации. Журналистика. СМИ» за три года изменились довольно заметно. В 2017 г. было выделено 13 более узких, по сравнению с общим, направлений. В 2020 г. обнаружилось, что потребовалось всего 7 (из прошлых) направлений, по которым удалось распределить фригурантов рейтинга. «Медиа» стали доминирующими среди них (в 2017 г. ими занимались 33 чел., в 2020 г. стали заниматься 62 - подавляющее большинство). В 2020 г. возросло количество авторов, занимающихся теорией информации (с 14 до 21 чел.), что закономерно в эпоху медиатизации и технологической трансформации медиа.

\section{Фактические области научных интересов, преподаваемые дисциплины ученых Ton-100 в 2017 и 2020 rr.}

\begin{tabular}{|r|l|r|r|}
\hline \multicolumn{1}{|c|}{ Области научных интересов } & 2017 & 2020 \\
\hline 1 & Медиа & 33 & 62 \\
\hline 2 & Чистая фрилология & 20 & - \\
\hline 3 & История книги, цензура, книговедение & 14 & 21 \\
\hline 4 & Бизнес-коммуникация, PR, реклама, маркетинг & 10 & 12 \\
\hline 5 & Административные должности & 6 & 1 \\
\hline 6 & Медицина & 3 & - \\
\hline 7 & «истая» экономика, менеджмент & 3 & - \\
\hline 8 & «Чистая» психология & 3 & - \\
\hline 9 & Теория информации, информатика & 2 & 2 \\
\hline 10 & Педагогика & 2 & - \\
\hline 11 & Политология & 2 & 1 \\
\hline 12 & «Чистая» география & 1 & - \\
\hline 13 & «истая» культурология & 1 & 1 \\
\hline & Всего авторов & 100 & 100 \\
\hline
\end{tabular}




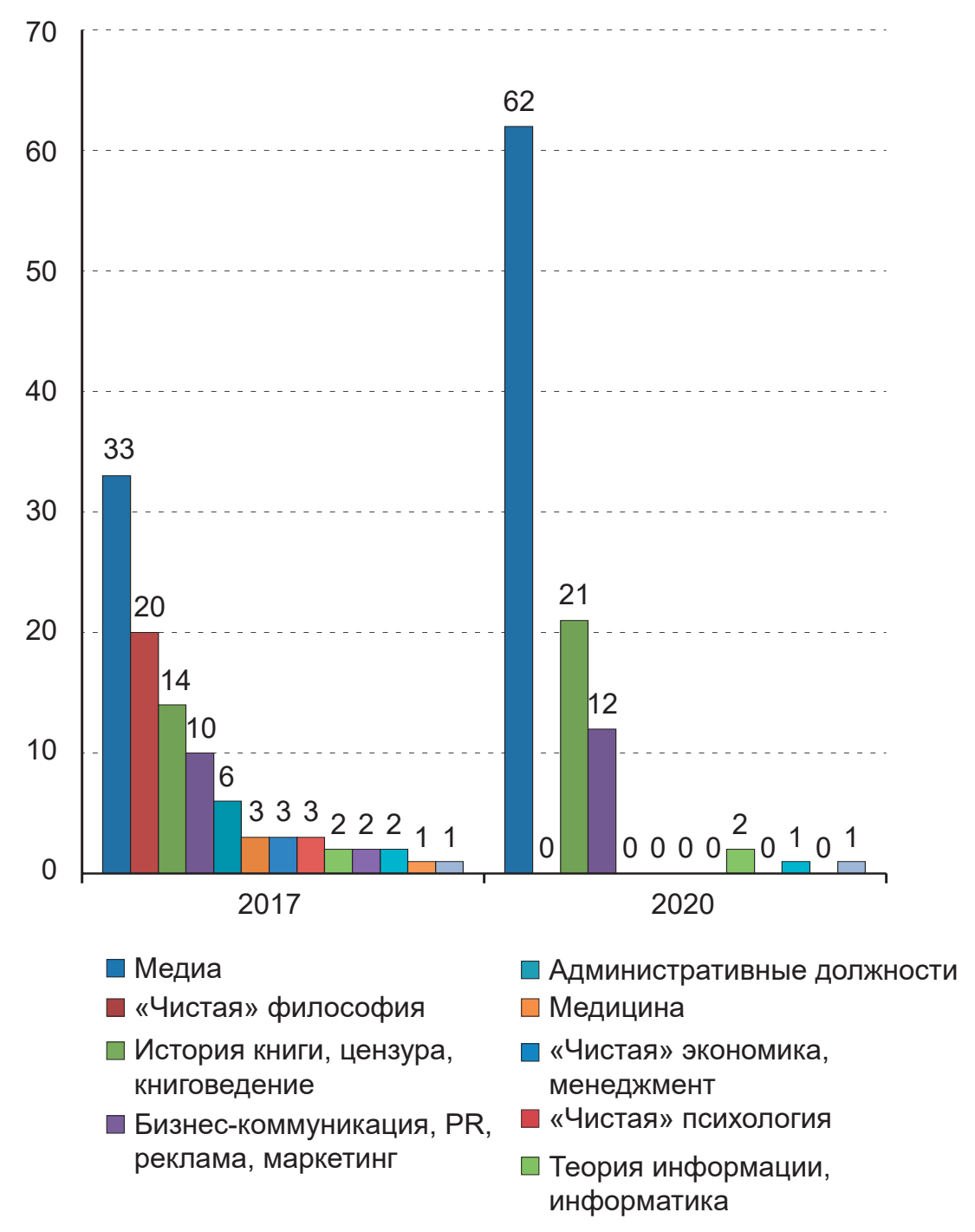

Рис. 7. Фактические области научных интересов, преподаваемые дисциплины ученых Топ-100 в 2017 и 2020 гг.

Немного увеличилось число ученых, к научным интересам которых можно отнести «бизнес-коммуникации, PR, маркетинг» (с 10 до 12 чел.), что увязывается с индустриальной теорией медиа, применением коммуникационных технологий, характерных для журналистики, в бизнес-коммуникациях, маркетинговых коммуникациях. Еще одно направ- ление, в котором выросло число фигурантов первой сотни - «история книги, цензура, книговедение» (с 14 до 21). Формат статьи не позволяет раскрыть список всех фигурантов, но наше исследование дает ответ на вопрос об увеличении этих данных: значительный рост объясняется включением в НЭБ ушедших из жизни работников библиотек из раз- 
ных городов России (в основном, из федерального центра).

Значительно уменьшилось число авторов, занимающих административные должности и имеющих в этой связи возможность увеличения наукометрических показателей (с 6 до 1). В списке 2020 г. отсутствуют авторы, к научным интересам которым относятся «чистая фрилология» (в 2017 г. было 20 авторов), «медицина» (в 2017 г. было 3), «чистая экономика, менеджмент» (было 3), «чистая психология» (было 3), «педагогика» (было 2 автора), «чистая география» (был 1). Слово «чистая» означает, что при детальном исследовании в 2017 г. выяснилось, что объектом исследования этих ученых не являлись «Массовая коммуникация. Журналистика. СМИ», включение в НЭБ произошло по их публикациям в средствах массовой информации. Можно сделать вывод о более верифицированных данных в НЭБ в 2020 г.

В целом среди авторов рейтинга широко представлены основные научно-образовательные школы журналистики: школа Московского государственного университета представлена 19 персоналиями, среди которых (называя не всех) Е.Л. Вартанова [9], М.В. Шкондин, О.В. Смирнова [10], Л.Г. Свитич [11], И.Д. Фомичева [12], В.Л. Иваницкий [13] молодые авторы А.В. Вырковский [14], М.И. Макеенко [15], А.А. Гладкова [16] и др. Среди других московских научно-образовательных школ, представленных в первой сотне 2020 г. - - Национальный исследовательский университет «Высшая школа экономики» (3 автора), Российский университет дружбы народов (2 автора), другие организации - по одному автору. В списке -
8 авторов, представляющих Российскую государственную библиотеку. Это - авторы, научными интересами которых является книговедение.

Петербургскую научно-образовательную школу в рейтинге большинство представляют ученые из СанктПетербургского государственного университета - 11 авторов, в числе которых, например, С.Г Корконосенко [17], Г.С. Мельник [18], Д.П. Гавра [19], Б.Я. Мисонжников [20] и другие, Санкт-Петербургский государственный экономический университет (4 автора), Санкт-Петербургский государственный институт культуры (3 автора), Российская национальная библиотека (4 автора) и др.

Традиционно сильной школой является школа воронежская, что подтверждает рейтинг 2020 г. в списке присутствуют 5 воронежских авторов, четверо из которых - представители Воронежского государственного университета. Назовем только одного - В.В. Тулупова [21].

Растет число представителей Челябинского государственного университета (трое в 2020 г. по сравнению с одним автором в 2017). Научно-образовательные школы Белгорода (три персоналии вошли в рейтинг), Таганрога (два автора в Топ-100 2020 г.) тоже представлены достойно. Остальные научно-образовательные организации представлены одним автором. Логично, что давно сложившиеся школы представляют большинство в рейтинге и 2020 г., и будут, видимо, доминировать и далее. В то же время молодые, развивающиеся научные школы так же представлены в Топ-100. Данные из НЭБ позволят в дальнейшем проследить динамику возникновения и развития таких школ. 


\section{Выводы}

Н-индекс по версии e-library лишь один из наукометрических показателей, позволяющих судить о научном публикационном вкладе ученых в развитие науки, наряду с другими - h-индекс по другим базам, количеством цитирования и т.д. Кроме того, этот показатель - «накопительный»: чем дольше существуют работы авторы, цитируются другими авторами, тем он выше. Молодые авторы здесь находятся в проигрышном положении. Этим показателем автор может управлять - «договорное» цитирование, соавторство и др. Работы авторов могут терять актуальность, количество цитирований определенной работы с годами уменьшается, но все они уже включаются в подсчет h-индекса. С этой точки зрения со временем h-индекс теряет свою актуальность.

В то же время в науку «врываются» новые имена, ученые, которые активно публикуются в настоящее время, статьи индексируются в международных наукометрических базах данных, в российском секторе WoS и т.д. В связи с этим НЭБ предлагает новые показатели для оценки научной состоятельности авторов: с весны 2021 г. в e-library появился новый наукометрический показатель - так называемый «процентиль по ядру РИНЦ». Он определяется на основе числа ссылок из ядра РИНЦ на работы, опубликованные за последние 5 лет в ядре РИНЦ. В соответствии с этим числом цитирований вся масса авторов в той или иной области знаний (тематике) разделяется на 100 частей (процентов, поэтому «процентиль») и выстраивается в рейтинг по этому проценту.
Так, по тематике «Массовая информация. Журналистика. СМИ» в настоящее время зарегистрировано 1679 авторов². Для того, чтобы определить процентиль автора, все они располагаются в списке в порядке убывания числа ссылок из ядра РИНЦ на их работы, опубликованные за последние 5 лет в ядре РИНЦ. В процентиле 1 будет 168 (1\% из 1680 ) авторов с наибольшим числом цитирований, в процентиле 2 - следующие 168 авторов (еще $1 \%$ с более низким числом цитирований и т.д. Таким образом, рейтинг по h-индексу, общему числу цитирований и т.д. дополняется еще одним показателем. Если процентиль будет введен в практику отчетности ученых научно-образовательных организаций и послужит базой для материального стимулирования или, например, будет основой для включения авторов в диссертационные советы и т.д., он будет мотивировать ученых на публикации в ядре РИНЦ.

Пока процентиль не введен в практику отчетности авторов, но можно предположить, что в будущем будет использоваться в качестве одного из важных наукометрических показателей для оценки публикационной активности за последние 5 лет, в отличие от h-индекса и других накопительных показателей за общее время научной деятельности ученого. Пока же показатель h-индекса и рейтинги авторов по этому показателю и другим привычным показателям (общее количество опубликованных работ, количество ссылок на эти работы)

2 Поск авторов // Научная электронная библиотека eLbrary. 2021. URL: https://elibrary.ru/ authors. asp. 
Вопросы теории и практики журналистики. 2021. Т. 10, № 4. С. 597-613

остаются важными показателями, авторы и афффилированные с ними научно-образовательные организа-

ции определяют по ним место ученого в научном мире по тематике опубликованных ими работ.

\section{СПИСОК ИСПОЛЬЗОВАННОЙ ЛИТЕРАТУРЫ}

1. Демина И.Н. Сравнительные характеристики публикационной активности ученых социально-гуманитарного профиля: проблемы и решения / И.Н. Демина // Вопросы теории и практики журналистики. - 2014. - № 4. - С. 131-146.

2. Демина И.Н. Критерии эффективности и продуктивности научных исследований в сфере журналистики / И.Н. Демина // Вестник Волжского университета им. В.Н. Татищева. - 2018. - Т. 1, № 1. - С. 105-114.

3. Корконосенко С.Г. Теория журналистики в России: научные школы / С.Г. Корконосенко // Век информации. - 2016. - № 1. - С. 48-58.

4. Хубецова З.Ф. Научно-образовательные школы журналистики стран ближнего зарубежья: репрезентация и апробация методики анализа (на материалах Беларуси, Казахстана и Украины) / З.Ф. Хубецова // Вестник Волжского университета им. В.Н. Татищева. - 2019. - Т. 1, № 4. - С. 169-180.

5. Терещенко Д.С. Статистический анализ дифференциации российских регионов по уровню публикационной активности / Д.С. Терещенко, В.С. Щербаков. - DOI 10.30680/ECO0131-7652-2019-9-132-154 // ЭКО. — 2019. — № 9 (543). — С. 132-154.

6. Сравнение наукометрических показателей публикационной активности вузов в Прикаспийских регионах России / Ю.М. Брумштейн, А.А. Баганина, Р.Р. Ахмедова, А.Н. Горбачева // Прикаспийский журнал: управление и высокие технологии. - 2016. № 1 (33). - C. 79-90.

7. Индекс Хирша в Российском индексе научного цитирования / В.А. Болотов, Н.Н. Квелидзе-Кузнецова, В.В. Лаптев, С.А. Морозова // Вопросы образования. 2014. - № 1. - С. 241-262.

8. Полянин А.Д. Недостатки индексов цитируемости и Хирша и использование других наукометрических показателей / А.Д. Полянин // Математическое моделирование и численные методы. - 2014. - № 1. - С. 131-144.

9. Вартанова Е.Л. Медиа и город: об актуальных взаимовлияниях / Е.Л. Вартанова // Меди@льманах. — 2020. — № 1 (96). — С. 8-19.

10. Смирнова О.В. Интегративная роль информационного обмена в медиапространстве в контексте оптимизации социальной практики / О.В. Смирнова, М.В. Шкондин. - DOI 10.34823/SGZ.2020.4.51411 // Социально-гуманитарные знания. — 2020. № 4. - C. 194-201.

11. Свитич Л.Г. Социология журналистики : учебник / Л.Г. Свитич. - Москва : Юрайт, 2019. - 397 c.

12. Фомичева И.Д. Ресурсная парадигма и нематериальные капиталы в СМИ / И.Д. Фомичева // Медиаскоп. - 2017. - № 1. - С. 8.

13. Иваницкий В.Л. Основы бизнес-моделирования СМИ : учеб. пособие / В.Л. Иваницкий. - 3-е изд., испр. и доп. - Москва : Юрайт, 2020. - 239 с.

14. Вырковский А.В. Различия в понимании и использовании базовых теоретических концепций у представителей медиаиндустрии и академической среды / А.В. Вырковский. - DOI 10.17223/19986645/64/16 // Вестник Томского государственного университета. Филология. - 2020. - № 64. - С. 277-289.

15. Вырковский А.В. Трудовые биографии молодых выпускников фракультета журналистики в крупном российском городе в 2010-е гг. / А.В. Вырковский, М.И. Макеенко // Журналистика в 2020 году: творчество, профессия, индустрия : материалы Междунар. науч.-практ. конф. / под ред. Я.Н. Засурского, Г.С. Филаткиной, О.Р. Алевизаки [и др.]. Москва, 2021. - С. 283-285.

16. Вартанова Е.Л. Цифровое неравенство, цифровой капитал, цифровая включенность: динамика теоретических подходов и политических решений / Е.Л. Вартанова, A.А. Гладкова. - DOI 10.30547/vestnik.journ.1.2021.329 // Вестник Московского университета. Серия 10: Журналистика. - 2021. — № 1. - С. 3-29. 
17. Корконосенко С.Г. Журналистика в модусе культуры: институциональный взгляд / С.Г. Корконосенко, М.А. Воскресенская. - DOI 10.34823/SGZ.2020.4.51402 // Социально-гуманитарные знания. - 2020. - № 4. - С. 108-119.

18. Мельник Г.С. Медиаиндустрия и медапотребление в глобализирующемся мире / Г.С. Мельник // Глобалистика-2020: глобальные проблемы и будущее человечества : электр. сб. тезисов участников VI Междунар. науч. конгресса, Москва, 18-22 мая 2020 г. - Москва, 2020. - С. 506-508.

19. Гавра Д.П. Основы теории коммуникации : учебник / Д.П. Гавра. - 2-е изд., испр. и доп. - Москва : Юрайт, 2020. - 231 с.

20. Мисонжников Б.Я. Будущее печати: новое качество / Б.Я. Мисонжников // Научные труды Северо-Западного института управления РАНХиГС. -2020 . - Т. 11, № 3 (45). - С. 59-61.

21. Тулупов В.В. Научно-педагогическая школа журналистики как центр культурного пространства региона / В.В. Тулупов // Медиа в современном мире. 59-е Петербургские чтения : материалы междунар. фрорума, Санкт-Петербург, 09-12 нояб. 2020 г. : в 3 т. Санкт-Петербург, 2020. - Т. 1. - С. 90-91.

\section{REFERENCES}

1. Demina I.N. Comparative characteristics of scientist's publication activity of social and humanitarian specialization: problems and solutions. Voprosy teorii i praktiki zhurnalistiki $=$ Theoretical and Practical Issues of Journalism, 2014, no. 4, pp. 131-146. (In Russian).

2. Demina I.N. Measure of potency and productivity of scientific research in the sphere of journalism. Vestnik Volzhskogo universiteta im. V.N. Tatishcheva = Vestnik of Volzhsky University after V.N. Tatischev, 2018, vol. 1, no. 1, pp. 105-114. (In Russian).

3. Korkonosenko S.G. Journalism theory in Russia: academic schools. Vek informatsii $=$ The Information Age, 2016, no. 1, pp. 48-58. (In Russian).

4. Khubetcova Z.F. Theoretical and Pedagogical Journalism Schools in Post-Soviet States: Representation and Test Methodology of Analysis (on the Materials of Belarus, Kazakhstan and Ukraine). Vestnik Volzhskogo universiteta im. V.N. Tatishcheva $=$ Vestnik of Volzhsky University after V.N. Tatischev, 2019, vol. 1, no. 4, pp. 169-180. (In Russian).

5. Tereshchenko D.S., Shcherbakov V.S. Statistical analysis of differentiation between russian regions by level of publications. EKO =ECO, 2019, no. 9, pp. 132-154. DOI: 10.30680/ ECO0131-7652-2019-9-132-154. (In Russian).

6. Brumshtein Yu.M., Baganina A.A., Akhmedova R.R., Gorbacheva A.N. Comparison of the universities printing activities scientometric indicators in Russian Caspian regions. Prikaspiiskii zhurnal: upravlenie $i$ vysokie tekhnologii = Caspian Journal Management and High Technologies, 2016, no. 1, pp. 79-90. (In Russian).

7. Bolotov V.A., Kvelidze-Kuznetsova N.N., Laptev V.V., Morozova S.A. The H-Index in the Russian science citation index. Voprosy obrazovaniya = Educational Studies, 2014, no. 1, pp. 241-262. (In Russian).

8. Polyanin A.D. Disadvantages of citation index and Hirsch and using other scientometrics. Matematicheskoe modelirovanie $i$ chislennye metody = Mathematical modeling and computational methods, 2014, no. 1, pp. 131-144. (In Russian).

9. Vartanova E.L. Media and the City: on the Current Interactions. MediaAl'manakh = MediaAlmanah Journal, 2020, no. 1, pp. 8-19. (In Russian).

10. Smirnova O.V., Shkondin M.V. The integrative role of information flow in the media space in the context of social practice optimization. Sotsial'no-gumanitarnye znaniya = Socgum-Zhurnal, 2020, no. 4, pp. 194-201. (In Russian).

11. Svitich L.G. Sociology of Journalism. Moscow, Yurait Publ., 2019. 397 p.

12. Fomicheva I.D. Resource paradigm and intangible capital in media. Mediaskop $=M e-$ diascope, 2017, no. 1, pp. 8. URL: http://www.mediascope.ru/en/2307. (In Russian).

13. Ivanitskii V.L. Fundamentals of business modeling media. $3^{\text {rd }}$ ed. Moscow, Yurait Publ., 2020. 239 p. 
14. Vyrkovskii A.V. Differences in the understanding and use of basic theoretical concepts in representatives of the media industry and the academia. Vestnik Tomskogo gosudarstvennogo universiteta. Filologiya $=$ Tomsk State University Journal of Philology, 2020, no. 64, pp. 277-289. DOI: 10.17223/19986645/64/16. (In Russian).

15. Vyrkovskii A.V., Makeenko M.I. Labor biographies of young graduates of the Faculty of Journalism in a large Russian city in the 2010 s. In Zasurskii Ya.N., Filatkina G.S., Alevizaki O.R., Makeenko M.I., Filatkina G.S. (eds). Journalism in 2020: Creativity, Profession and Industry. Materials of International Research Conference. Moscow, 2021, pp. 283-285. (In Russian).

16. Vartanova E.L., Gladkova A.A. Digital divide, digital capital, digital inclusion: dynamics of theoretical approaches and political decisions. Vestnik Moskovskogo universiteta. Seriya 10: Zhurnalistika = Moscow University Journalism Bulletin, 2021, no. 1, pp. 3-29. DOI: 10.30547/vestnik.journ.1.2021.329. (In Russian).

17. Korkonosenko S.G., Voskresenskaya M.A. Journalism in the Mode of Culture: Institutional View. Sotsial'no-gumanitarnye znaniya = Socgum-Zhurnal, 2020, no. 4, pp. 108-119. DOI: 10.34823/SGZ.2020.4.51402. (In Russian).

18. Melnik G.S. Media industry and media consumption in a globalizing world. Globalistics-2020: Global issues and future of humankind" at Lomonosov Moscow State University: collection of articles of the VI international scientific congress. Moscow, May 18-22, 2020. Moscow, 2020, pp. 506-508. (In Russian).

19. Gavra D.P. Basic Theory of Communication. Moscow, Yurait Publ., 2020. 231 p.

20. Misonzhnikov B.Ya. The future of printing: new quality. Nauchnye trudy Severo-Zapadnogo instituta upravleniya RANKhiGS = Scientific works of the North-West Institute. of Management of the Russian Academy of Science, 2020, vol. 11, no. 3, pp. 59-61. (In Russian).

21. Tulupov V.V. Scientific and pedagogical school of journalism as the center of the cultural space of the region. Media in the Modern World. $59^{\text {th }}$ St. Petersburg Readings. Materials of the International Forum, Saint Petersburg, November 09-12, 2020. Saint Petersburg, 2020, vol. 1, pp. 90-91. (In Russian).

\section{ДЛЯ ЦИТИРОВАНИЯ}

Демина И.Н. Наукометрические показатели медиаисследователей в элек-тронной библиотеке e-library / И.Н. Демина. — DOI: 10.17150/2308-6203.2021.10(4).597-613 // Boпросы теории и практики журналистики. — 2021. — Т. 10, № 4. - С. 597-613.

\section{FOR CITATION}

Demina I.N. Scientometric Indicators of Media Researchers in the e-library. Voprosy teorii i praktiki zhurnalistiki = Theoretical and Practical Issues of Journalism, 2021, vol. 10, no. 4, pp. 597-613. DOI: 10.17150/2308-6203.2021.10(4).597-613. (In Russian). 